the virtues of rest. Hiaving read a translation of Koch's classic paper on the etiology of tuberculosis, he built himself a modest laboratory in his own home. Out of its ashes sprung the present Saranac Laboratory-the first of its kind in the United States. Trudeau wrote little on clinical subjects; but his laboratory studies are contained in a large number of valuable papers, including experiments on immunity and on the effect of fresh air on tuberculous rabbits. He was the first president of the National Association for the Study and Prevention of Tuberculosis. His optimism and charm endeared him to all his patients, perhaps the most famous of whom was Robert Louis Stevenson.

\section{Convention on High Vacua}

The Society of Chemical Industry is sponsoring a convention on high vacua under the presidency of Sir Charles Darwin, director of the National Physical Laboratory, which is being organised by Mr. L. L. Maitland, director of British-American Research, Ltd., to be held at Gleneagles during October 12-13. Among the topics to be discussed are the applications of high vacua to plastics, dehydration, distillation generally and the distillation of fatty oils, the metallurgical industry and nuclear physics and atomic energy. Full opportunity will be provided for discussion. Information on accommodation and travel arrangements can be obtained from Mr. L. L. Maitland, British-American Research, Ltd., Block E.2, Hillington North, Glasgow, S.W.

\section{Photo-electric Spectrometry Group}

AN association has been formed of those interested in instruments for photo-electric spectrometry and their applications. It has been named the Photoelectric Spectrometry Group, without prejudice to its possible future affiliation to an existing scientific body. The inaugural meeting of the Group was held in Cambridge on July 16. Out of about a hundred and twenty who were invited, sixty-four attended. New instruments were on view and papers were read by Dr. E. R. Holiday (London Hospital) on "Adaptation of the Filger Spekdzer and Medium Spectrograph for Photoelectric Work", and by Mr. G. H. Beaven (Thornton Research Centre, "Shell" Refining and Marketing Co., Ltd.) entitled "Notes on the Operation, Maintenance and Servicing of the Beckman Model D.U. Spectrophotometer".

The following were appointed officers of the Group : Chairman: Dr. J. R. Edisbury, Research Department, Lever Bros. and Unilever, Ltd., Port Sunlight; Vice-Chairman : Mr. G. Fi. Beaven, Thornton Research Centre, "Shell" Refining and Marketing Co., Ltd., P.O.B. No. I, Chester; Hon. Secretary: Mr. W. H. Storey, Unicam Instruments (Cambridge), Ltd., Arbury Works, Cambridge; Hon. Treasurer : Mr. J. R. Stansfield, Hilger and Watts, Ltd., 98 St. Pancras Way, London, N.W.1 ; Committee: Mr. C. G. Cannon, Physics Department, University of Reading; Mr. B. S. Cuoper, Research Department, General Electric Co., Ltd., Wembley ; Dr. J. G. A. Griffiths, A.D.I. (Sc.), Air Ministry, Whitehall, S.W.1; Dr. E. R. Holiday, Research Department, London Hospital, E.1 ; and Dr. F. Wokes, Ovaltine Research Laboratories, King's Langley, Herts. Subjects on which it is proposed to hold further meetings or whole-day conferences are flame photometry (jointly with the Institute of Physies Industrial Spectroscopic Group), fluorescence, photo-electric recording of spectra, stray light, and reflexion spectra.
A bulletin will be issued periodically for private distribution to members and will contain reports of meetings with details of papers and discussions. It will also include abstracts, a question and answer section, and give information about new designs and the location of spares for existing instruments. The subscription is $10 \mathrm{~s}$, per annum, commencing October 1, and includes the cost of the bulletin. Membership forms can be obtained on application to the honorary secretary.

\section{National Research Council of Canada: Medical Fellowships}

Medrcal fellowships have been awarded by the National Research Council of Canada to thirty-one graduates in medicine to enable them to pursue postgraduate research during 1948-49. Distribution of the awards by the universities at which they will be held is as follows : McGill, 8 ; Montreal, 1 ; Queen's, 4 ; Toronto, 7 ; Western Ontario, 8; Manitoba, 1; Oxford, 1; Zurich, 1. These fellowships vary in amount from 1,500 to 2,500 dollars, depending on the previous training and experience of the candidates. The Division of Medical Research of the National Research Council also makes grants-in-aid to Canadian universities for medical research studies on approved subjects. During the present year, 118 such grants, valued at 264,173 dollars, are being held. The nominal value of the thirty-one medical fellowships awarded this year is 64,600 dollars.

\section{Physical Society of London: Award of Charles Vernon Boys Prize}

The Charles Vernon Boys Prize of the Physical Society, given annually for distinguished research in experimental physics, is being awarded this year to Prof. S. Tolansky in recognition of his work in interferometry. The Prize will be presented at a meeting of the Society on October 8, when Prof. Tolansky will give an address on "Current Investigations with Multiple-Beam Interferometry". Prof. S. Tolansky has held the chair of physics at the Royal Holloway College, University of London, since 1947, and has done extensive research work in optics and spectroscopy; during the war years he was engaged on research in connexion with atomic energy.

Prof. R. W. Wood, professor of experimental physics at the Johns Fopkins University since 1901 and research professor since 1937, will give an address to the Society before the award of the Charles Vernon Boys Prize, his subject being "Spontaneous Deformation of Crystals". Prof. Wood is receiving an honorary degree of D.Sc. from the University of Oxford.

\section{Lectures on the Atomic Age}

The Sir Fialley Stewart Trust has arranged a course of six free lectures on "The Atomic Age", to be given at the Memorial Hall, Farringdon Street, London, on Tuesdays, beginning October 26, at 6 p.m. The speakers will be Prof. M. L. Oliphant, on "The Scientific Achievement" ; Prof. P.M. S. Blackett, on "The Military Consequences of Atomic Energy"; Mr. R. F. Harrod, on "The Economic Repercussions of Atomic Power" ; Lord Russell, on "Our Scale of Values in the Atomic Age" ; Mr. Lionel Curtis, on "The Political Repercussions"; and Prof. D. W. Brogan, on "America as Atlas". For free reserved seats application should be made to the Secretary, Sir Halley Stewart Trust, 167 Strand, London, W.C.1. 